\title{
Teaching Large Classes with Clickers: Results from a Teaching Experiment in Comparative Politics
}

Marcela Velasco, Colorado State University

Gamze Çavdar, Colorado State University

ABSTRACT Instant-response technologies, or clickers, are student response devices that help address some of the challenges involved in teaching large classes, namely student motivation and engagement with the material. This article evaluates a diverse set of teaching and learning strategies enabled by clicker technology and their impact on student learning. We highlight five aspects of teaching that are enhanced by the use of clickers, describe an experiment comparing student performance in traditional and clicker lectures, and report results of a survey of student perception about the effects of this technology on motivation, learning, and engagement. We argue that while the use of clickers is time-consuming for the instructor and presents a steep learning curve, clickers improve teaching effectiveness in large classes and hold promise for increasing student learning.

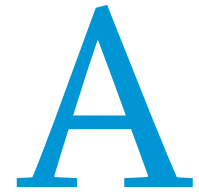

lthough large classes have become common in higher education, many instructors are not fully prepared to address the challenges they present. These challenges include low student interest, irregular class attendance, low grades, and limited studentinstructor interaction. Furthermore, research shows that increased class size has "a negative and statistically significant impact on the amount learned, instructor rating, and course rating" (Monks and Schmidt 2010,15). Facing some of these challenges, we adopted instant-response technology, or "clickers," in each of our sections of Introduction to Comparative Government and Politics, which normally enroll 110-190 students. Clicker use refers to "an electronic application where a receiver located in the instructor's computer captures information from student keypads in response to questions posed by the instructor" (Premkumar and Coupal 2008, 146).

We share the results of a course redesign to introduce clickers. We analyzed the restructured lectures and how we incorporated clickers, organized a learning experiment, and gathered survey results. The work is based on two courses taught in the fall semester of 2010. Section 1 had 108 students enrolled and met three times a week in 50-minute lectures. Section 2 enrolled 151 students and met twice a week in 75-minute lectures. The teaching experiment was performed in section 2, and both sections produced data for the survey. Here we argue that while the use of

Marcela Velasco is an assistant professor in the department of political science at Colorado State University. She can be reached at Marcela.Velasco@colostate.edu. Gamze Çavdar is an associate professor in the department of political science at Colorado State University. She can be reached at Gamze.Cavdar@colostate.edu. clickers is a time-consuming endeavor that presents the instructor with a steep learning curve, using clickers makes teaching large classes more effective and promises to increase student learning.

\section{HOW TO INCORPORATE CLICKERS INTO THE CLASSROOM}

Incorporating clicker questions into lectures requires a major restructuring of the course slides or outlines. We find that at most, five or six questions can be included in a 50- to 75-minute lecture. Incorporating clicker questions is time-consuming work, and instructors need to plan the pace of the lecture accordingly. We also find that student participation rises considerably when responses receive a grade or when students know that some clicker questions will also appear in the exams. ${ }^{1}$ However, instructors should specify which questions are graded and which are not.

Our analysis of the way we incorporated clicker questions into our lectures revealed that the technology enhanced the following learning and teaching strategies: (1) student attentiveness, (2) problem-solving group work, (3) real-time assessment of student comprehension, (4) critical thinking skills, and (5) simulation exercises. Although this is not an exclusive list, it does address some of the main pedagogical challenges confronting instructors of large classes.

\section{Student Attentiveness}

Maintaining student attentiveness is a major challenge in large classrooms (Bunce, Flens, and Neiles 2010; Hoekstra 2008) for several reasons. First, many university students hold jobs and often work full time (Perna 2010, xiii) and may have trouble finding a proper balance between academic and work responsibilities. 
Table 1

Example PowerPoint Presentation for Traditional Lectures

SLIDE 1

SLIDE 2

SLIDE 3

SLIDE 4

\begin{tabular}{lll}
\hline Lecture: & Lecture: & Lecture: \\
$\begin{array}{l}\text { Ethnicity } \\
\text { Definition }\end{array}$ & Ethnicity is context-dependent & Ethnicity is socially constructed: \\
Characteristics & Examples: & The case of Rwanda \\
& $\begin{array}{l}\text { 1. Kurds-Turks } \\
\text { 2. Jews-Palestinians } \\
\text { 3. Tutsis-Hutus }\end{array}$ \\
\end{tabular}

Table 2

\section{Sample PowerPoint Presentation for Clicker-Integrated Lectures}

SLIDE 1

Clicker Question:

1. (Not graded) Turks and Kurds share the same religion but speak different languages; Palestinians and Jews speak different languages and have different religions; Tutsis and Hutus speak the same language and share the same religion.

What defines ethnicity, then?

a. Physical characteristics.

b. Socio-economic status.

c. Ethnicity is contextdependent.
SLIDE 2

SLIDE 3

SLIDE 4

\section{Lecture:}

What is ethnic identity? Why is it significant?

a social group that is believed

to be distinct in history, culture, language, and physical characteristics, etc. none of the above might exist: characterized by a sense of belonging

socially constructed

context-dependent
Clicker Question:

2. (Graded) Which of the following could NOT be one of the implications of the sentence, "Ethnicity is socially constructed"?

a. Ethnicity is trivial.

b. Ethnicity is unreal.

c. Ethnicity is politically irrelevant.

d. What ethnicity means to people evolves over time.
Video \& Lecture:

Trailer of Hotel Rwanda (30 seconds)

The evolution of Tutsis and Hutus from socioeconomic categories to hostile ethnic groups
Second, students have ready access to disruptive electronic devices that they often use during class. Third, a large classroom fosters disruptions coming from physical movements and noise by other students. Thus, one of our main concerns was to keep students engaged during class time.

In a traditional lecture without clickers, instructors use a number of teaching methods to maintain attention by raising questions, using slides, or showing photographs and videos (table 1). Although these methods are useful, they keep students in a passive role.

Alternatively, in lectures that use clickers (or clicker lectures), the instructor organizes the lectures around questions that require instant student feedback (table 2). In other words, clicker lectures include all of the elements used in traditional lectures, but, in addition, they pose questions every 15 to 20 minutes that require students to use their clickers to answer (table 2). In addition, providing a question for students to answer when they arrive in the classroom motivates them to get ready for the lecture and set up their clickers. As explained in detail, because the goal is to keep students' attention, they are not expected to know the correct answer to every question.

In general, clicker questions aimed at keeping students engaged may pursue various objectives. Questions based on the reading materials encourage students to come to the class prepared by reading in advance. Opinion or polling questions give students the opportunity to anonymously express their views on any subject. Clickers can keep the answers anonymous while still showing that a particular student voted. Answers to these questions may coincide with society-wide attitudes and help the instructor make an abstract topic seem more relevant. Questions to stimulate discussions enhance participation and help students learn from each other or after deliberation. Review questions inform instructors whether students have generally understood a topic allowing instructors to focus on areas that require attention.

\section{Problem-Solving Group Work}

Problem-solving group work is especially helpful when the correct answer ratio of a question is low. Students are asked to turn to their neighbors and explain the reasons behind their responses. A two- to three-minute discussion is usually sufficient. As expected, the percentage of correct answers generally improves after discussions. Having students discuss a question in small groups breaks up the routine, gives students a chance to rethink their responses, and provides an opportunity to interact with their classmates. More correct answers following this group-work exercise lends support to findings that students effectively learn from each other (Slavin 1995).

\section{Real-Time Assessment of Student Comprehension}

Posing a set of questions at the end of the lecture gives students a chance to review the lecture and test their knowledge, while the 
Table 3

\section{Sample Questions for Building Critical Thinking Skills}

HELPING BUILD CRITICAL THINKING SKILLS: INTERPRETATION

\author{
According to Karl Marx, which one of the following can be \\ characterized as superstructure? \\ a. gender \\ b. the system of economic production \\ c. class relations \\ d. the level of technology \\ e. the relations of production
}

HELPING BUILD CRITICAL THINKING SKILLS: INFERENCE
Which one of the following statements could be drawn from the base-superstructure relationship (as described by Marx)?

a. Some European countries developed capitalism earlier than others because of their Protestant work ethics.

b. Muslim societies are not likely to experience capitalist development.

c. Cultural values of a nation are going to remain constant over time regardless of regime type.

d. All advanced capitalist societies share a similar culture.

e. Nationalist feelings are too strong to be eradicated by socialism. instructor gets feedback on whether the lecture material needs further clarification. Assigning a grade to these questions greatly increases students' motivation to be more attentive to the lecture content.

\section{Critical Thinking Skills}

Clickers have the potential to enhance critical thinking skills. Five distinct critical thinking skills are description, application, recognition of assumptions, inference, and analysis (Greenlaw and DeLoach 2003). While writing assignments increase critical thinking (Çavdar and Doe 2012), these skills could be also developed through multiple-choice questions (table 3). We inform our students that our clicker questions will slowly move from description to analysis during the semester. More challenging questions require students to move beyond memorizing what the lecture or reading material stated and analyze the information. Asking challenging questions that require critical thinking keeps the questions interesting throughout the semester.

\section{Simulation Exercises}

Clickers can be used to construct simulations as shown by this example on political ideologies and electoral systems. After a brief lecture on political ideologies, students form a political party with four to five other students and choose their party's ideology from among liberalism, socialism, and social democracy. Groups are expected to work in class to prepare a campaign speech in accordance with their ideology. They are asked specifically to address taxes and health care and are encouraged to be creative. After 10 to 15 minutes, volunteers from each ideology come to the podium and present their campaign speeches. The classroom is divided into districts, and a general election allows all students to vote for competing parties using clickers. The results are tabulated according to different electoral systems. After a brief lecture, the instructor poses several clicker questions on the advantages and disadvantages of different systems of representation, and students witness first-hand how the three parties fare under each system.

\section{DO CLICKERS INCREASE LEARNING?}

Instant-response technology can enhance instructional strategies, but does it support learning? Research in various disciplines examining the impact of clickers on learning report small but positive effects (Hoekstra 2008; Morling et al. 2008; Sevian and Robinson 2011; Shapiro and Gordon 2012). Although based on a small sample, our own research confirms these claims. We also considered the impact of the timing of the lectures during the semester and found that the clicker's positive effect on learning wears off toward the end of the semester.

The experiment compared learning results from traditional lectures (the control group) with those from clicker lectures (the treatment group) and found that clickers have some positive effects on student learning. In traditional lectures (see table 1), the instructor would talk uninterrupted for 20-30 minutes, often integrating PowerPoint presentations, photographs, or short videos into the lectures. The clicker lectures, lasting about 20-30 minutes, incorporated the same supporting materials, but to increase student engagement additionally included five multiple-choice questions in the actual presentation, as illustrated in table 2 . These questions, asked during the lectures, were designed to focus student attention, test prior knowledge, or check immediate understanding of new concepts.

Each lecture type was followed by five multiple-choice questions to test how effectively students had learned the material covered. In the clicker lectures the five test questions were different from the clicker questions included throughout the lecture. During the semester, six traditional and six clicker lectures were conducted (table 4). Colorado State University's Institutional Review Board evaluated the research protocol and required student consent for participation in the research. All students received a recruitment e-mail and listened to a recruitment speech by our graduate assistants. In all, 125 students signed consent forms; of these 59 participated in the teaching experiment, and 122 answered the survey. Of the 59 students who participated in the learning experiment, 20 were freshmen, 24 sophomores, 9 juniors, and 6 seniors; there were 21 female students and 38 male students; 48 students identified as white and 11 as nonwhite or no reply; and 22 were political science or history majors, and the rest were nonmajors or undecided. The topics of the 12 lectures were randomly assigned to the lecture types.

The lecture data was analyzed using a randomized blocked design (RBD) blocking on students. First, the model treats each student as a block allowing us to focus on the variable of primary concern, in this case performance in clicker versus traditional lectures, while controlling for the effects of variability between students (i.e., gender, major, year in college, or any other individual attribute that might influence performance). Except for a few students who participated in either a clicker lecture or a traditional class but not in both, every student has performance scores for 
Table 4

Lecture Topics

\begin{tabular}{llll} 
CLICKER LECTURES (TREATMENT) & DATE & \multicolumn{1}{c}{ TRADITIONAL LECTURES (CONTROL) } & DATE \\
\hline Ethnicity, Nation, Citizenship & Aug 31 & State, Government, Regime & Sep 2 \\
\hline Political System in the U.K. & Sep 7 & Emergence of Democracy in the U.K. & Sep 14 \\
\hline Characteristics of Authoritarianism in Egypt & Sep 30 & Obstacles to Democracy in Egypt & Oct 5 \\
\hline GDP, Gini Index, HDI & Oct 7 & How Authoritarian Regimes Stay in Power & Oct 26 \\
\hline Marxism & Nov 9 & Bolshevik Revolution & Nov 11 \\
\hline Imperialism and Colonialism & Nov 16 & Economic Liberalization in Russia & Dec 7
\end{tabular}

difference between the proportions of correct answers obtained in clicker versus traditional lectures began to narrow. The last column in table 6 presents the $P$-values of a comparison of means within each of the six sets of treatment versus control lectures. The analysis produces only two statistically significant results during times 2 and 3 , a set of lectures delivered in the middle of the semester. Lower student performance Table 5

Analysis of Mean Scores by Type of Lecture using Randomized Block Design (POLS 241-02 Fall 2010)

\begin{tabular}{lccccc} 
TYPE OF LECTURE & DF $^{\text {a }}$ & $\begin{array}{c}\text { PROPORTION } \\
\text { CORRECT }\end{array}$ & $\begin{array}{c}\text { STD. ERR } \\
\text { MEAN }\end{array}$ & $\begin{array}{c}\text { LOWER } \\
\text { MEAN }\end{array}$ & $\begin{array}{c}\text { UPPER } \\
\text { MEAN }\end{array}$ \\
\hline Treatment (Clicker) & 257 & 0.752 & 0.017 & 0.718 & 0.784 \\
\hline Control (Traditional) & 257 & 0.685 & 0.019 & 0.647 & 0.721 \\
\hline
\end{tabular}

aln a RBD the error term for comparing methods would be the student by time-set by method interaction. With no missing observations it would have $(59-1) *(6-1) *(2-1)=290$ degrees of freedom. However, with 33 missing observations, as was the case in this experiment, the DF equal 257.

clicker and traditional lectures. The estimates were adjusted for student effects that were assumed to be random.

Second, the RBD allows us to determine if the clicker effects depend on time sets, which were treated as six pairs. The lectures were thus paired with respect to students, who were generally exposed to both lecture types. The RBD produced mean estimates based on the model and adjusted for students and missing data. So, if one high performing student missed the class, the model assumed that the estimate would be higher, and vice versa. In addition, when computing overall treatment and control means, the model averaged the dates as if students had equal attendance for each date/lecture-type combination. In sum, the 59 students constituted 59 blocks exposed to 12 lectures that were paired into six time sets during the semester.

As table 5 shows, our research found that clicker lectures, which were designed to increase student engagement, produced higher mean scores on multiple-choice questions than traditional lectures. Table 5 shows statistically significant results and highlights that overall, clicker lectures obtained a higher proportion of correct answers (0.75) compared to traditional lectures (.69). In other words, student scores increased by $6 \%$ in clicker lectures, suggesting that stronger engagement with the instructor and the material with the help of clickers increases their understanding.

Table 6 presents the results of the 12 lectures and when they were delivered. The results show that in general, clicker lectures obtained a higher percentage of correct answers than the traditional lectures (ranging from 1 to 10 points higher). The model also takes into account the effect of time on student performance by pairing lectures into six time sets that included one clicker and one traditional lecture taught within proximate periods of time. This approach allows a time-sensitive comparison of student performance and demonstrates that as the semester advanced, the dent engagement aided by clicker technology and learning in large classes. But do students perceive the same connection? To test this question we conducted a survey to see whether students felt that the technology helped them with learning.

\section{STUDENT PERSPECTIVES OF CLICKER USE}

The literature reports that student reactions toward using clickers are mostly positive (Berry 2009; Elicker and McConnell 2011; Evans 2012; Hoekstra 2008; Shaffer and Collura 2009). To evaluate student perceptions on the impact of clickers, in the last week of classes we administered an opinion survey in both sections. Again, following IRB recommendations, 125 consented to take the survey, and 122 completed it. Students who consented to take the survey were 56 freshmen, 44 sophomores, 16 juniors, and 9 seniors; 57 female students and 68 male students; 100 students identified as white and 25 as nonwhite or no reply; and 43 were political science or history majors, 82 were nonmajors or undecided. ${ }^{2}$

Survey questions appraised student learning, motivation to learn, engagement with the course, incentives to attend class, and overall opinions of the technology (see table 7). We conducted a series of least square means analyses and found no statistically significant results suggesting that student perceptions on clicker technology differed with respect to gender, major, year in college, or ethnicity/race.

The survey presents consistently high results in answers to questions on understanding of the subject matter and engagement. Most students agreed that clickers helped them understand lectures (79\%), concepts $(74 \%)$, and course material $(70 \%)$, although fewer supported the statement that clickers helped them prepare for the exams (57\%). Students overwhelmingly agreed that clickers offered ways to test their knowledge (89\%) and kept them engaged with the subject ( $75 \%$ ) and with instructor questions $(71 \%)$. 
Table 6

Analysis of Mean Scores by Lecture and Time using Randomized Block Design (POLS 241-02 Fall 2010)

\begin{tabular}{|c|c|c|c|c|c|c|c|c|}
\hline METHOD & $\begin{array}{l}\text { TIME } \\
\text { SET }\end{array}$ & DATE & DF & $\begin{array}{l}\text { PROPORTION } \\
\text { CORRECT }\end{array}$ & STD. ERR & $\begin{array}{l}\text { LOWER 95\% } \\
\text { CONF. INTERVAL }\end{array}$ & $\begin{array}{c}\text { UPPER 95\% } \\
\text { CONF. INTERVAL }\end{array}$ & $\begin{array}{l}\text { P-VALUE } \\
\text { FOR T v. C }\end{array}$ \\
\hline Treatment & 1 & $8 / 31 / 10$ & 257 & 0.714 & 0.031 & 0.649 & 0.771 & 0.174 \\
\hline Control & 1 & $9 / 2 / 10$ & 257 & 0.656 & 0.035 & 0.585 & 0.721 & \\
\hline Treatment & 2 & $9 / 7 / 10$ & 257 & 0.803 & 0.027 & 0.745 & 0.850 & 0.000 \\
\hline Control & 2 & $9 / 14 / 10$ & 257 & 0.649 & 0.034 & 0.580 & 0.713 & \\
\hline Treatment & 3 & $9 / 30 / 201$ & 257 & 0.831 & 0.026 & 0.772 & 0.877 & 0.044 \\
\hline Control & 3 & $10 / 5 / 10$ & 257 & 0.752 & 0.032 & 0.683 & 0.810 & \\
\hline Treatment & 4 & $10 / 7 / 10$ & 257 & 0.814 & 0.027 & 0.754 & 0.862 & 0.120 \\
\hline Control & 4 & $10 / 26 / 10$ & 257 & 0.755 & 0.030 & 0.690 & 0.809 & \\
\hline Treatment & 5 & $11 / 9 / 10$ & 257 & 0.712 & 0.033 & 0.642 & 0.772 & 0.409 \\
\hline Control & 5 & 11/11/1o & 257 & 0.676 & 0.034 & 0.605 & 0.739 & \\
\hline Treatment & 6 & $11 / 16 / 10$ & 257 & 0.594 & 0.035 & 0.523 & 0.661 & 0.743 \\
\hline Control & 6 & $12 / 7 / 10$ & 257 & 0.609 & 0.037 & 0.534 & 0.680 & \\
\hline
\end{tabular}

Table 7

\section{Student Opinion Survey on the use of Clicker Technology (POLS 241 Sections 1 and 2 Fall 2010, $N=122)$}

\section{QUESTION}

T AGREE NEUTRAL T DISAGREE

Learning

1 Clicker questions helped me understand lectures.

2 Clicker questions helped me understand concepts.

3 Clicker questions helped me prepare for the exams.

4 Clicker questions confirmed that I understood the course material.

5 I believe I learned more in this class thanks to the use of clickers.

$\begin{array}{rrrr}79 & 10 & 11 & 2 \\ 74 & 16 & 10 & 2 \\ 57 & 27 & 16 & 2 \\ 70 & 20 & 9 & 2 \\ 46 & 34 & 20 & 3\end{array}$

\section{Motivation}

6 Clicker questions motivated me to learn.

$\begin{array}{llll}29 & 44 & 27 & 3\end{array}$

7 I found clicker questions interesting.

8 Clicker questions were a fun way to explore different concepts.

$52 \quad 34$

$34 \quad 14$

\section{Engagement}

9 Clicker questions gave me opportunities to better engage with my classmates.

10 Clicker questions enabled me to test my knowledge of material that was covered on that day.

11 Lectures that integrated many clicker questions kept me engaged with the material.

12 I am more likely to respond to instructor questions if responses are gathered through clickers.

$\begin{array}{rrrr}25 & 32 & 43 & 3 \\ 89 & 7 & 5 & 2 \\ 75 & 13 & 12 & 2 \\ 71 & 17 & 11 & 2\end{array}$

\section{Attendance}

13 Clicker questions made it more interesting to attend class.

$43 \quad 34 \quad 23 \quad 3$

14 I prefer lectures where clickers are used

15 I am more likely to attend the classes that use clickers than the ones without clickers.

\section{Overall Evaluation of Clicker Technology}

16 Overall, I was very satisfied with the use of clickers in the class.

$54 \quad 30$

They also found that clicker questions were interesting (52\%). A minority of students agreed that clickers offered opportunities to engage with their classmates ( $25 \%$ ), however, we offered few opportunities for collaboration.
Far less agreement occurred with respect to whether clickers helped students learn more in this course $(46 \%)$, increase their motivation (29\%), or make exploring different concepts more enjoyable $(39 \%)$. We speculate that students considered the fullness of 
learning opportunities that go beyond the use of interactive technology, and include other activities delivered by the instructor, and their own personal tasks reading, preparing notes, and completing assignments. Forty three percent of students agreed that clickers made attending class more interesting, and between $54 \%$ and $58 \%$ agreed that they preferred classes that use clickers. We did not use clickers to take attendance, and many students wrote comments in the survey rejecting the use of clickers to take attendance. Overall, students were satisfied with the use of clickers in the course (58\%), but only $39 \%$ preferred that clickers be used in all other courses. Thus, students still value a good lecture whether or not it uses clickers.

\section{IN CONCLUSION, DO WE RECOMMEND USING CLICKERS?}

Thanks to clickers, we now have more students attending our lectures, and we enjoy channeling their energy from one activity to another. We also appreciate the opportunities to actively involve them with the class material, we appreciate the dynamism that using clickers helps create in the classroom, and we very much
Instant response devices increase instructor effectiveness and student learning by allowing students and instructors to engage in real-time assessments of knowledge gained during lectures. Our lecture redesign had a positive effect on teaching by making classes more engaging, and our experiment found a positive correlation between this technology and learning. However, the results need to be corroborated by similar experiments in other courses. Finally, the survey confirmed that students find clickers useful.

Therefore, we recommend use of this technology with some reservations. Since it involves investing considerable time in redesigning lecture materials, instructors should plan accordingly. Following these recommendations will likely maximize the teaching and learning benefits of this new technology.

\section{ACKNOWLEDGMENTS}

The research was funded by a grant from Colorado State University's Institute for Teaching and Learning in 2010-2011 and was the recipient of the American Political Science Association's

\section{Although some results are not statistically significant and would require more data, the overall analysis of the data gathered on the lectures suggests a positive connection between increased student engagement aided by clicker technology and learning in large classes. But do students perceive the same connection?}

like that our students listen carefully to our lectures. Our research largely agreed with the consensus in the literature that clickers do contribute to student learning. However, we do have a few recommendations.

First, instructors must allow a significant amount of time to learn about the technology and ways of incorporating clicker questions into their lectures. Technical difficulties emerge and becoming familiar with the technology requires significant preparation. Universities that employ technical staff often organize clicker training sessions, and online support is also available. However, we find that long-distance support of the software is not as efficient as on-campus support. Thus, we recommend being familiar with the clicker literature that describes potential and actual problems associated with this instrument (Cole and Kosc 2010; Dallaire 2011; Duncan 2011; Evans 2012; Milner-Bolotin, Antimirova, and Petrov 2010; Premkumar and Coupal 2008; Sevian and Robinson 2011).

Second, we strongly recommend clickers as an optional tool for students. We used the technology that requires students to use a remote, not to download an application for their smartphones. In our case, we found that about one-third of our students did not have the clicker and were not willing to purchase it unless it was required. We anticipate a similar situation with smartphones since not all students might own one or be willing to use the technology. We typically assign some extra credit to students who use the clickers consistently and who have a high percentage of correct responses.

Lastly, we caution against using clickers in administering exams or taking attendance until the software is significantly improved. Common problems include batteries running out or clickers failing to capture student data even if the student has chosen an answer. Allowing students to miss $20 \%$ to $25 \%$ of the clicker questions gives some room for such failures.
2011 Annual Award for Learning Innovation Using Information Technology. We would like to thank James zum Brunnen for his help with the statistical analysis, and Amy Lewis, Jamie Barringer, Theresa Jedd, and Caitlin Wall for collecting classroom data. Special thanks go to Sue Doe for her critical feedback.

\section{NOTES}

1. We required only $70 \%$ to $75 \%$ of the questions posed during the semester to be correct to allow some margin for missing classes and technical problems.

2. Please note that 125 students signed permission forms to participate in the study. We obtained individual demographic and academic data from our class lists and not from the survey itself, which was anonymous and only asked the 17 questions listed in table 7 . Three people who agreed to participate in the study, failed to turn in the survey.

\section{REFERENCES}

Berry, Janice. 2009. "Technology Support in Nursing Education: Clickers in the Classroom." Nursing Education Perspectives 30 (5): 295-98.

Bunce, Diane, Elizabeth Flens, and Kelly Neiles. 2010. "How Long Can Students Pay Attention in Class? A Study of Student Attention Decline Using Clickers." Journal of Chemical Education 87 (1): 1438-443.

Çavdar, Gamze, and Sue Doe. 2012. "Learning through Writing: Teaching Critical Thinking Skills in Writing Assignments." PS: Political Science and Politics 45(2) 298-306.

Cole, Stephanie, and Gregory Kosc. 2010. "Quit Surfing and Start 'Clicking': One Professor's Effort to Combat the Problems of Teaching the U.S. Survey in a Large Lecture Hall." The History Teacher 43 (3): 397-410.

Dallaire, Danielle H. 2011. "Effective Use of Personal Response 'Clicker' Systems." Teaching of Psychology 38 (3): 199-204.

Duncan, Douglas. 2011. “Tips for Successful Clicker Use.” Mercury 40 (4): 14-15.

Elicker, Joelle, and Nicole McConnell. 2011. "Interactive Learning in the Classroom: Is Student Response Method Related to Performance?" Teaching Psychology 38 (3): 147-50.

Evans, Heather. 2012. "Making Politics "Click": The Costs and Benefits of Using Clickers in an Introductory Political Science Course." Journal of Political Science Education 8 (1): 85-93. 
Greenlaw, Steven A., and Stephen B. DeLoach. 2003. "Teaching Critical Thinking with Electronic Discussion." The Journal of Economic Education 34 (1): 36-52.

Hoekstra, Angel. 2008. "Vibrant Student Voices: Exploring Effects of the Use of Clickers in Large College Courses." Learning, Media and Technology 33 (4): 329-41.

Milner-Bolotin, Marina, Tetyana Antimirova, and Anna Petrov. 2010. "Clickers Beyond the First-Year Science Classroom." Journal of College Science Teaching 40 (2): 14-18.

Monks, James, and Richard Schmidt. 2010. "The Impact of Class Size and Number of Students on Outcomes in Higher Education." Cornell University, School of Industrial and Labor Relations. http://digitalcommons.ilr .cornell.edu/workingpapers/114/.

Morling, Beth, Meghan McAuliffe, Lawrence Cohen, and Thomas M. DiLorenzo. 2008. "Efficacy of Personal Response Systems ('Clickers') in Large, Introductory Psychology Classes." Teaching of Psychology 35: 45-50.
Perna, Laura W. 2010. New Research and Its Implications for Policy and Practice. Sterling, VA: Stylus Publishing.

Premkumar, Kalyani, and Cyril Coupal. 2008. "Rules of Engagement: 12 Tips for Successful Use of 'Clickers' in the Classroom.” Medical Teacher 30: 146-49.

Sevian, Hannah, and William E. Robinson. 2011. "Clickers Promote Learning in All Kinds of Classes-Small and Large, Graduate and Undergraduate, Lecture and Lab." Journal of College Science Teaching 40 (3): 14-18.

Shaffer, Dennis, and Michael Collura. 2009. "Evaluating the Effectiveness of Personal Response System in the Classroom." Teaching of Psychology 36: 273-77.

Shapiro, Amy M., and Leamarie T. Gordon. 2012. "A Controlled Study of ClickerAssisted Memory Enhancement in College Classrooms." Applied Cognitive Psychology 26 (4): 635-43

Slavin, Robert E. 1995. Cooperative Learning: Theory, Research, and Practice. Boston: Allyn and Bacon. 